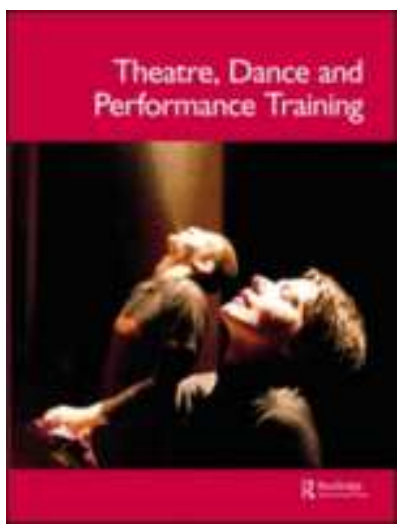

\title{
From Walking and Talking to Cartwheels and High Cs: An examination of practice-based laboratory work into physio- vocal integration.
}

\begin{tabular}{|r|l|}
\hline Journal: & Theatre, Dance and Performance Training \\
\hline Manuscript ID: & Draft \\
\hline Manuscript Type: & Article \\
\hline Date Submitted by the \\
Author: & n/a \\
\hline Kemplete List of Authors: & $\begin{array}{l}\text { Bryon, Experience; Central School of Speech and Drama, Post } \\
\text { Graduate }\end{array}$ \\
\hline & $\begin{array}{l}\text { voice, movement, vocal dance, breath, integrative performance } \\
\text { practice, centre }\end{array}$ \\
\hline
\end{tabular}

\section{SCHOLARONE" \\ Manuscripts}


Title

From Walking and Talking to Cartwheels and High Cs: An examination of practice-based laboratory work into physio-vocal integration.

\begin{abstract}
Following a series of investigative workshops inquiring into the possibilities of the vocal body, artists of Experience Vocal Dance Company trained intensively in an experimental method called the Integrative Performance Practice (IPP), developing an exacting technique that allows the performer the freedom to completely integrate unlimited movement and uncompromised voicing including bel canto singing.
\end{abstract}

This article shares the work of the company through case study, exercises and application to performance propositions examined through the methodology of Transdisciplinarity. The article reflects on how many approaches to voice and movement within the disciplines of acting, singing and dancing can promote disintegration of the physio-vocal instrument. It touches on the implications of integrating the performance instrument through the notion of the psycho-physical and addresses certain inter and cross-cultural perspectives present in recent discussions about voice and movement.

Finally, it lays out exactly how with the IPP it was discovered that everything needs to originate from the breath/body; how language and skill sets are best rooted in process-based terms; and that action, be it vocal, physical or emotive, needs to initiate from awareness, reconfiguring the artist as self, working within an active aesthetic. As a key finding, a most precise articulation of centre is described in detail and related to physio-vocal praxis.

\title{
Introduction
}

This article contains the results of a five-year "moment" within a larger, ongoing project concerning the integration of acting, singing and dancing. The entire project has spanned three countries and has taken place over 17 years to date. (To be published in an upcoming book for Routledge, 2013, titled Integrative Performance: Practice and Theory for 
the Interdisciplinary Performer). It included studies in acting for opera, movement for actors and acting for dance within collaborative, devised and more traditional models of theatre making. However, before it was possible to reconcile the different skill sets and vocabularies of the disciplines of acting, singing and dance, it became clear that some aspects of the exacting physicalities and underlying cultures within the disciplines of singing and dance were complex and often contradictory. They needed to be worked through in a "moment" of their own. Of course, sounding and moving structures are a valuable part of many preparatory exercises and creative explorations for the actor, singer and dancer. However, we saw a gap in knowledge surrounding the possibilities of an integrated practice of dancing and singing that does not compromise either discipline on their own aesthetic terms. In resolving some of the differences in the techniques taught to vocalists and movers, we re-configured where the practitioner begins in terms of 'awareness'. We worked to demystify conflicting notions of 'centre', clarified a breathing practice for the vocal body, and documented a most exacting use of the iliopsosas muscle system. Through a coordinated 'dynamic alignment', handstands, cartwheels and movement from the floor to leaping became possible without compromising voice or movement. This article outlines these key elements of the practice. The work took place in 
the studio and was ultimately shared in peer reviewed environments and public performances as Experience Vocal Dance Company (EVDC). 1 Many of the practical outcomes of this work challenged the ways we approached language, skill sets and even the artist as self. It is hoped that what is shared might contribute to existing knowledge, and in some cases offer a new approach to interdisciplinary explorations within performance practice(s).

The enquiry and its players

A fundamental question for this stage of the research was: how far can we go in integrating voice and movement without compromising either on its own terms? Can one sing and dance without compromising the vocal line, pitch, articulation, or intonation; without the loss of upper harmonics, resonance or timbre? Is it possible to sing and dance without radically adjusting the choices in range of movement and without

\footnotetext{
EVDC has been presented as a Keynote for the International Movement Conference at the Moscow Art Theatre, and at The Embassy Studio in London, arranged by CETT. EVDC has performed in NYC and Germany at the Westside Dance Project, The Playhouse at the Abrons Arts Centre, Staatsoper Hannover Ballet Studio, Movement Research, Dance Theatre Workshop, The New Dance Group's The Exchange, the Vox Novus Composer's Voice series, and at the 92nd Street Y. It was part of a TV documentary Art Or Something Like It, and was featured in Backstage NYC, in an article by Lisa Jo Sagolla titled Experience Bryon's Integrative Performance Practice.
} 
compromising flexibility, strength, line, and balance? Could one sing upside down, or while leaping, doing back bends, or rolling on the floor?

To do these seeming impossible tasks we learned that it was not about putting two disciplines together, with the separate skill sets, different embodied understandings, and conflicting conditioning practices activated as part of the different performance aesthetics required. We were working toward physio-vocal integration. We were not interested in coming up with a multi- or even inter-disciplinary method that brings singing and moving together in a parallel or hybrid model. Most importantly, we were not aiming to create an aesthetic, genre or style born from a crossing or colliding of the disciplines; we were aiming for a practice that could work within a myriad of applications. We drew from a methodology that was born outside performance practices, an idea that has emerged from the social and political sciences, quantum and string theory: Basarab Nicolescu's notion of Transdisciplinarity.

\begin{abstract}
Artists from both New York City and London joined the endeavour. We had three actors who self-identified as knowing how to voice and move but who did not consider themselves singers or dancers. We had three opera singers who self-identified as non-dancers, with one being a yoga teacher. We had a puppeteer who had sung alternative rock music. We
\end{abstract}


had three musical theatre performers who saw themselves respectively as: actor first, singer/dancer last; dancer first, acting second with a little voice training; and singer first who could move and act. We had dancers, trained to varying degrees in Ballet and Modern techniques, who did not see themselves as singers. We also had a speech therapist, a movement specialist and a few devised theatre performers who did not primarily identify with one discipline. As Artistic Director and author of the study, I had been trained as a "straight" actor, musical theatre performer, opera singer, and in dance. I had performance experience in each, and had directed, taught and choreographed within the various discrete forms and crossovers of the performance disciplines. I had also practiced yoga for over 20 years and was a certified teacher.

In short, there were at any point a myriad of language and skill sets in the room. What was interesting, especially when leaving training and conditioning and approaching rehearsal, where performance values would be a concern, was what was considered important by each practitioner as the aesthetic goal shifted. Many returned to the values of their primary disciplines (especially when they self identified as being an actor who sings, or a dancer who acts for instance); issues that arrived out of this will be discussed in the second half of this article. We worked at these points to return to an integrated active aesthetic, a way of doing, 
that would increasingly become the kernel of the practice through a field of transdisiplinarity. But first- the practice.

\title{
Centre? Which centre?
}

Centre is articulated by practitioners of different disciplines and different cultures in different ways. In modern dance, such as that of Hawkins and Graham techniques as beautifully articulated by Eric Franklin (2002), movement is often described as initiating in the "pelvis". In acting, the breath centre can reside "deep within the body, in an area roughly three finger-widths below your navel" (Benedetti 1997, p.19). It can be also be "located in the middle of the belly" where "The natural progression of the breath goes freely from the middle of the belly outward to the periphery in all directions" (Lugering 2007, p.49). In describing an exercise on "breathcontrol" Zarrilli describes it as "the region two to three inches below the navel" (Zarilli 2009, p.26).

\author{
Understandings of centre are often influenced by Eastern dance and fight \\ forms. For instance, in Kathakali, the highly stylised Indian dance-drama \\ centre is at the "root of the Navel" or Nabhi Mula (Zarrilli 2000. P93). In \\ Buyo, a traditional dance-mime form from Japan, a "power center \\ ...could be imagined as a ball of steel in the centre an (sic) triangle \\ whose apex is the anus and whose other two angles are the corners of
}


the pelvis at the level of the navel" (Azuma cited in Barba 2006, p.140). Eastern centres are about the dance of energy as released through the breath-body (recognising no mind/body split), a harnessing and readiness, poised, and in flow. This "energy" is known throughout the east as Ki (Korea), Chi (China), Qi (Japan) and Prana or Pranavayu (India).

Energy and its relationship to the body and breath is crucial for the physiovocal practitioner working in the realm of the active aesthetic of disciplinarity rather than towards an aesthetic form. We found that we needed to be very exacting about where centre is, how we return to it, its relationships to breath in motion, breath and sound and moreover ourselves as performers.

For us, the action of breath as it engages and stays in constant contact with the perineum became key.

\section{Perineum as centre}

We found that when drawing awareness to areas, regions or internal and difficult-to-sense places articulated through imagery—which is always subjective — the abdominal muscles hooked in. This created a domino effect of tensions throughout the body when sounding and moving at the same time. The voice often broke, or upper harmonics were lost, and 
balance, line and flexibility was compromised. We needed to integrate the physio-vocal instrument by working from and constantly returning to an even lower and more precise spot.

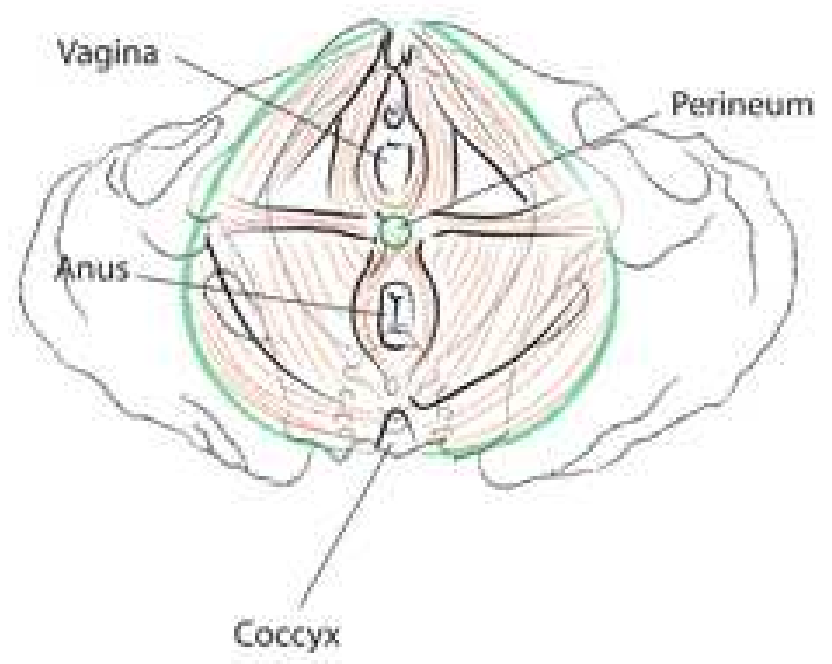

R. Zacharek c2ocs

Figure 1 Perineum (female)

The perineum sits at the bottom of the pelvic floor between the genitals and the anus. On the exhale, it will contract upwards in the direction of the top of the head. On the inhale, the pelvic floor releases downward as a symptom of the diaphragm's release as it displaces the lower internal organs. The experience of staying connected with the perineum as centre can feel odd and even scary at first as you give up a sense of "control" that tensions within a particular attachment to form or aesthetic might allow. 
We found that when working from the perineum, the versions of centre articulated above were realized in the breath body as a symptom of this action. Interestingly, we also found that to isolate too far forwards on the pelvic floor off the perineum, as in Kegel exercises², created a sharpening of the pitch and a hardening of tone; to go too far back towards the anus created a dampening of the tone and at times a flatness of pitch.

The perineum corresponds directly with the Mula Bandha or the "root chakra" in the Indian tradition. Swami Buddhananda's account of its benefits directly speaks to our findings.

Moola Bandha (perineal contraction) stimulates both the sensorymotor and the autonomic nervous systems in the pelvic region. When moola bandha is performed, stimulation activates parasympathetic fibers emerging from the pelvic spinal cord....The overall effect of stimulating both parasympathetic and sympathetic nervous systems is to rebalance these two major components of nervous activity in the body. This has very definite repercussions on the hypothalamus (responsible for the complete endocrine system) which relays its information to the whole limbic (emotional) system

2 Kegel exercises, named after gynecologist Dr. Arnold Kegel (1884-1981), are often prescribed for vaginal or pelvic prolapse, urinary incontinence and sexual dysfunction. 
and the cerebral cortex (outer layer of the brain). (Buddhananda 2000, p.3)

\begin{abstract}
Principal artist of the company Karen Jolicoeur noted that, "An awareness of connection to (and resulting initiation from) and/or perineum is not the same thing as attempting to make things happen from a certain place. Also, if one has a sense of the abdominal muscles as centre, one has some reprogramming to do / ideas to change"! (Jolicoeur 2007, Rehearsal Report)
\end{abstract}

\begin{abstract}
Awareness
A foundation of our work was "coming from awareness". This differs from "focus", which can be disintegrating. For instance, one way we learn this is in the difference between two simple tasks. When an artist is asked to "focus on their left big toe" (the reader might wish to try this), what most often happens is that the person stops breathing; their tongue might get rooted at the top of their palate, and they lose the awareness of the rest of the room.... In contrast, when they are asked to "draw awareness to your left big toe", the toe can be brought into the field of awareness along with breath, the room, the entire body and the ability to witness, all in readiness to move to the next task. We do various tasks within various structures towards training, conditioning, and rehearsal, from a field of
\end{abstract}


awareness. Awareness is non-verbal, but not to be confused with the nonintellectual or no-mind. If we can be aware that we have thoughts, and moreover be aware that we have feelings, then we are by definition not our feeling or our thoughts. We have them, and our job is to do the task through, with, including, and in integration with these. The task, however, is where the directional energy resides. We constantly ask ourselves when we have difficulty in a task not what we did wrong, but at which point did we leave awareness. A key aspect of the practice is to constantly return to centre from awareness at each and every breath/task.

This also means that we always do a doing for the first time. We never repeat what felt right or what looked good on someone else. This shifts the language and doing of the practice into process-based terms within an active aesthetic:

What has not been fully considered is a look at performance practice. The way of meaning making. Not meaning as in signs and signifiers in text (which include composition, choreography and stage direction)...But the way of meaning making. The practice of practice. In literary analysis and in performance theory we look at the meaning and meaning making but not the way of meaning making...For us Vocal Dancers this is why the shape of the 
movement is arbitrary. Even if you are looking at someone who is doing it from centre. This is why the sound of the tone should never be repeated in the quest for the correct production. This is why we do not use words such as mask, position, placement, or posture... This is why we start in awareness before utterance, action, movement or emotive expression. (Bryon 2006, workshop report)

\section{$\underline{\text { Three-Part Breath }}$}

In order to maintain the integrity of the entire breath/body in movement, we found that a breath dance that maintained a constant connection in awareness to the perineum was key. This constant connection meant that the intake (not inhale, as this takes superfluous muscles and does not make use of the natural vacuum effect within our physiology) started as a release of the pelvic floor. The exhale, often voiced (working exactly the opposite from many singing trainings) initiated from a contraction of the perineum, resulting in a hollowing of the belly first, then a contraction in the intercostals and a slight descent of the sternum. This particular action on the exhale is called reverse breathing in some yogic practices. For us, however, there is a dynamic, non-tensioned resistance to the collapse in the intercostals and sternum, so that we are ready and poised for the next intake, which again releases the perineum. In doing this particular breathdance, the better one gets at accessing awareness of the perineum as 
centre, the less tension results. We found that in working toward integration all movement and all sound emerged from this breath-dance.

We learned this in constructive rest, standing, rolling, and practicing sun salutations while sounding scales. Each person's challenges in allowing the breath to remain in contact with the perineum through the intake and exhale/voicing were different. These challenges were often the result of patternings learned from other disciplines and forms, in addition to habitual life patternings. These patternings directly translated to a leaving of the iliopsoas muscle system, often shifting to the larger muscles in the legs and the arms and temporarily leaving the central upward direction of the perineal connection with a corresponding loss of awareness.

\section{$\underline{\text { lliopsoas }}$}

The iliopsoas muscle is comprised of two parts. The iliacus and psoas muscles are joined to each other laterally along the psoas tendon. The iliopsoas originates anterior to the transverse processes of the T12 to L5 vertebrae and inserts into the lesser trochanter of the femur. 3

3 For two detailed discussions on the workings of the lliopsoas see: The Psoas Book by Liz Koch and Pelvic Power by Eric Franklin. 


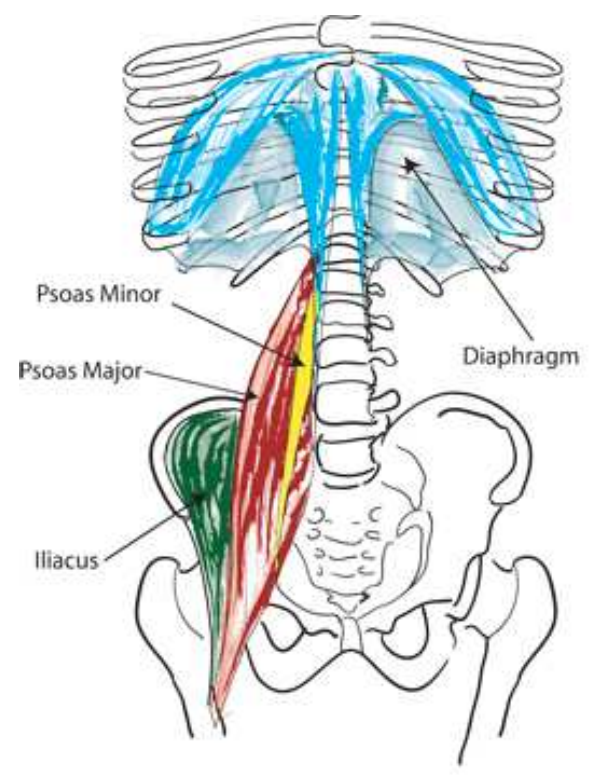

Figure 2 lliopsoas

Many practices in dance and movement work with locating this muscle system as a centre of the body; however, in practice it is quite elusive, since it is hard to feel. When you do engage it properly, the general experience is that of balance, with a release of the abdominals and an expanded sense of the breath body. Plotting a path from the big toe up the inside of the leg towards the psoas is the key to hearing no jiggle in the voice while leaping. The more exacting the engagement of the iliopsoas, the less extraneous tensions result, with less interference with the breath/body. The physio-vocal practitioner relies on a most exacting use of the iliopsoas. We have numerous exercises that work with the iliopsoas. In sharing with the group between NYC and London I wrote the following. 
There is a new exercise...It is designed to help re-pattern the muscles of the leg, feet and lower back to allow for the engagement of the psoas and long muscles in the abs (as opposed to the short that will impede the diaphragm movement in our breath). It is also designed to balance the action from the big toe all the way up to the inside of the leg to the psoas. This will allow more stabilization in our leaps and balances. (I will be choreographing more energetically)...It is important that we do this with the breath so that we pattern the three part breath and perineum action with the toe, inside leg, psoas connection. (Bryon 2007, group correspondence 12/8)

\section{$\underline{\text { Hands and Arms }}$}

Much like plotting the path from the big toe through the inside of foot up the inside of the leg to the psoas as a preliminary action for every time a foot touched the floor, we had a mirror action in the arms. The key was plotting the path from the webbing between the thumb and pointer finger through the inside of the forearm, diagonally under the arm pit down the back body and resting on the base of the scapula, drawing it down away from the ears. This was employed with counter-rotations of the arms, creating the necessary independence of the tongue, neck, jaw, shoulder blade, sternum and scapula. This, when mastered as one action 
from awareness with continuous connection to the perineum and isolation of the psoas, was the secret to our eventually successfully voiced handstands and cartwheels.

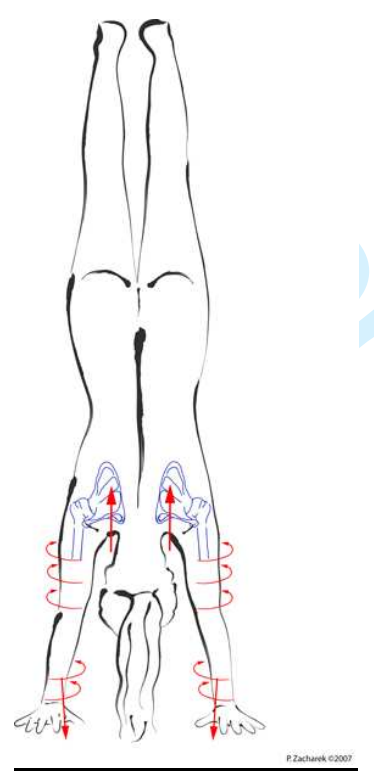

Figure 3 Arm Rotations

\section{Dynamic Alignment}

For us, alignment in motion was maintained with a lengthening on every intake and exhale, assisted by the perineal contraction moving upwards towards the top of the head. This allowed the creation of distance, back, front and centre equally, between the pelvic girdle, the diaphragm, shoulder girdle and jaw. With this, we maintain the three-part breath when folded over and in any physical position. In Sara's Vocalise, one of the 
many compositions written by David Wolfson, Musical Director EVDC, the act of dropping and rolling to the floor in dynamic alignment is illustrated. ${ }^{4}$

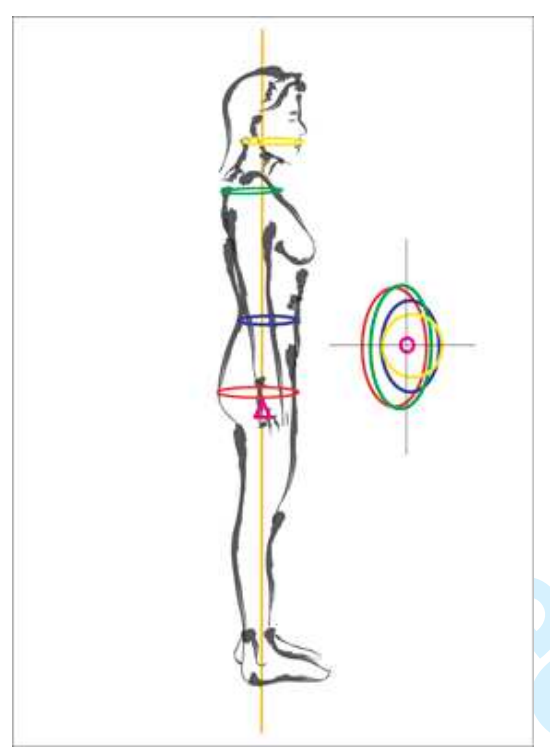

Figure 4 Dynamic Alignment

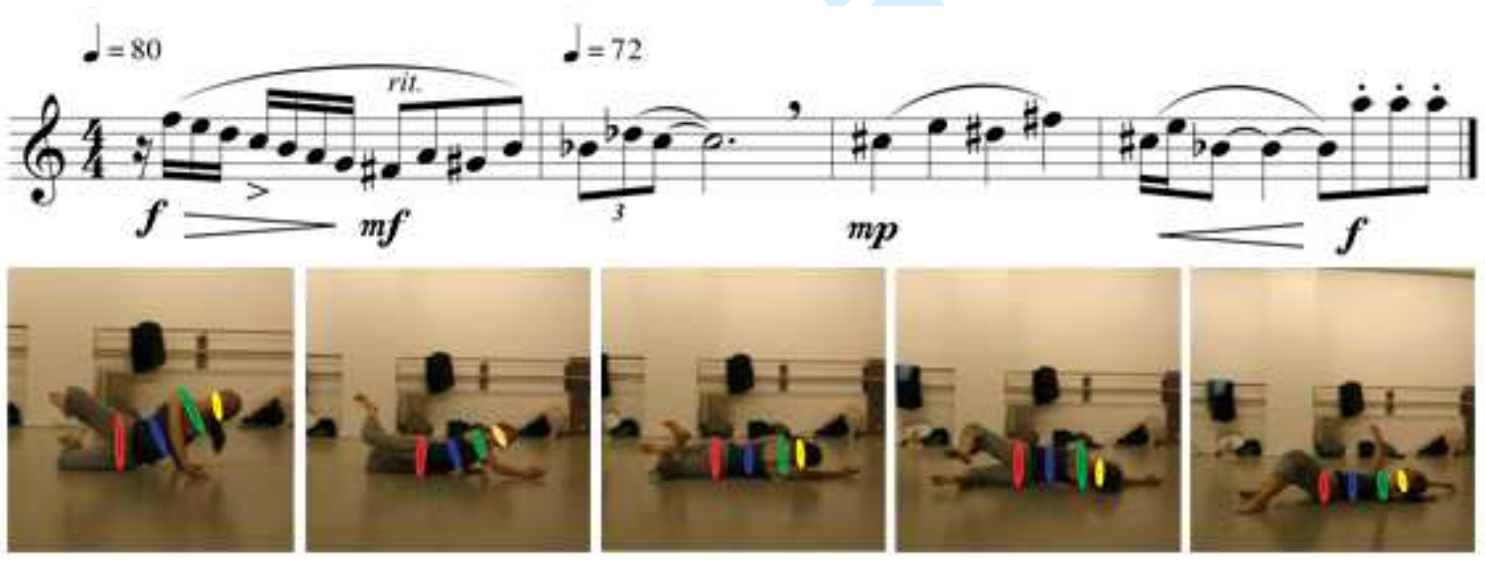

Figure 5 Alignment in Motion

4 This work and others can be seen in their entirety on the EVDC Youtube site: see http://www.youtube.com/user/Experiencevocaldance\#p/u 


\section{Tongue/Jaw Breath direction}

The ring (see Fig 4 \& 5) around the jaw is important. A gentle expansion along the back of the neck, in concert with a breath connected to the perineum, releases the palate upwards, the tongue forward and poises us to exhale or voice, plotting the path of the air off the throat. The directional energy of the breath path is through the level of the philtrum, (the cleft between the nose to the upper lip), rather than lower through the mouth (see Fig 6). This draws from both bel canto singing and Danish speech pathologist Sven Smith's Accent Method. We found that if we sang on the throat in a technique reminiscent of belt or folk, that extreme movement would pinch or jiggle the sound. Staying off the throat and in connection to centre, neck rolls are possible while sustaining a vocal line.

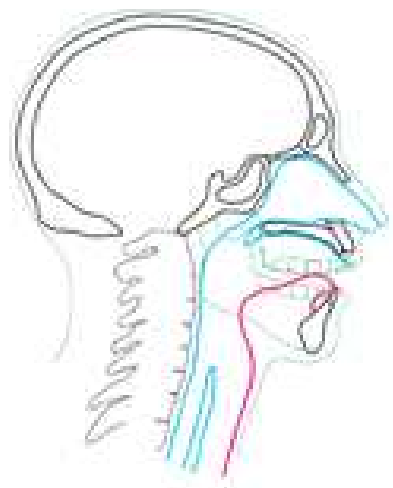

Intake

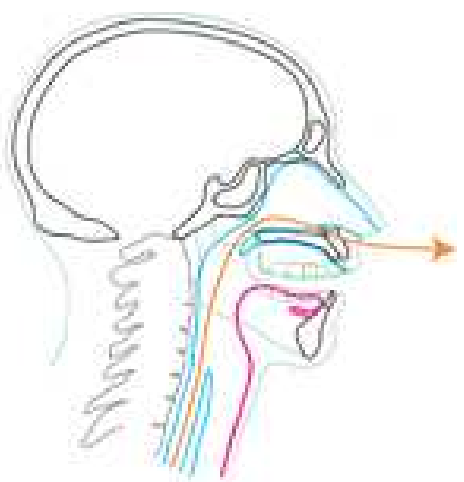

Voicing

pachenuteapot

Figure 6 Tongue, Jaw and Breath Action 


\section{Putting it together}

Although this has been written linearly, these aspects of the practice all happen concurrently, as one integrating action for the physio-vocal practitioner. Awareness first and throughout; then intake, which happens in concert with the release of the pelvic girdle, quickly succeeded by the intercostals' expansion followed by the sternum. At the same time, the expansion of the "rings", with the tongue releasing forward and jaw releasing. Then a suspension (never a holding), and the exhale or voicing begins with a simultaneous perineal contraction and breath exhaled in the direction of the philtrum, followed in quick succession by a resisted contraction of the intercostals and then the sternum-and it begins again, with a constant return to centre from awareness.

\section{$\underline{\text { Vaccai }}$}

To condition, warm-up and train we used the ariettas of Nicola Vaccai from his Practical Method of Italian Singing. They provide incremental vocal challenges to which I added choreography, integrating increasingly difficult movement challenges for the physio-vocal practitioner. They range from walking to rolling, leaping, fast footwork, circling the entire torso and various ways of putting pressure on the hands and arms. 
The final 3 figures show a range of movement sequences (taken out of context in select phrases) that were practiced as part of the Vaccai series using the Integrative Performance Practice.

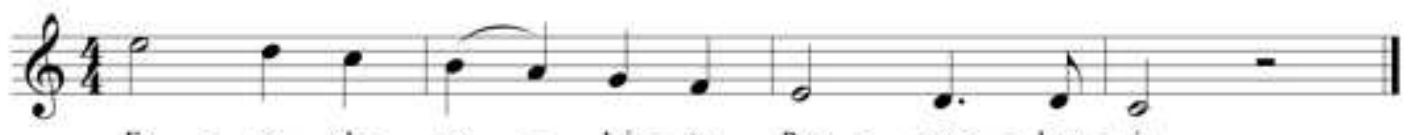

$\mathrm{Fa}$ - ce che pa - Ipi - ta Pre - ssoa - Imo - rir.

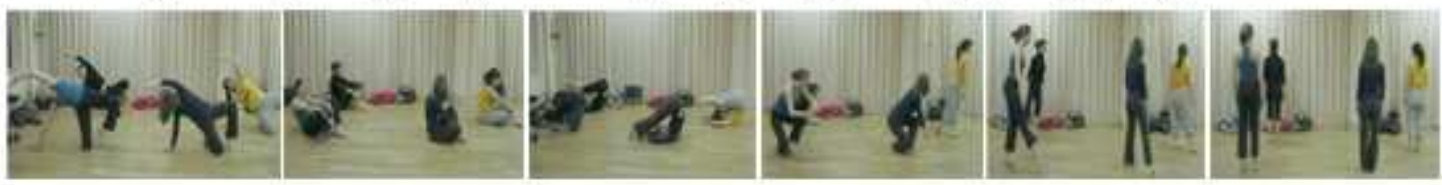

Figure 7 Rolling to standing
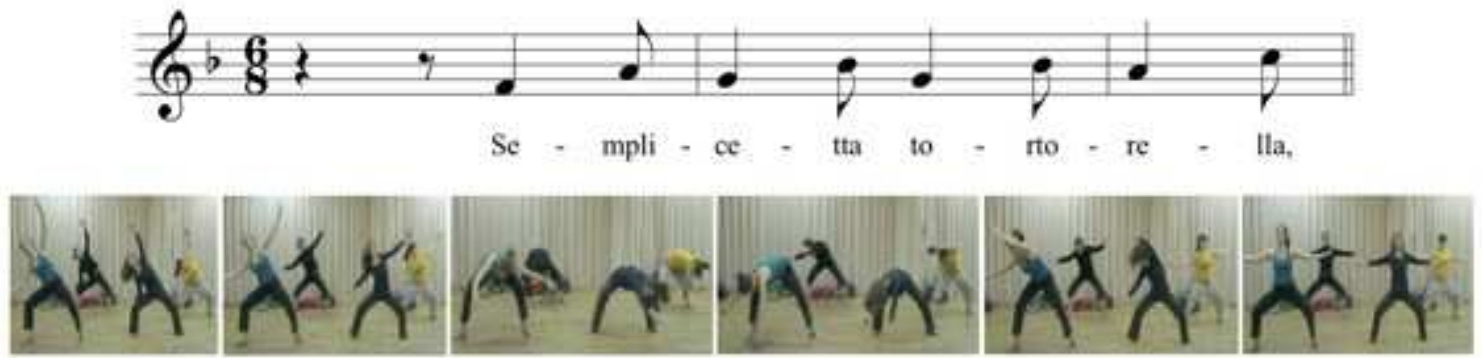

Figure 8 Torso Rotations

Figure 9 Leaping 
Analysis and Reflection

As author of the study, I was aware of scholarship examining performance from "cross-cultural" or "inter-cultural" perspectives, especially with regard to merging the practices of the East and West; however, our focus was the cultures of the practices "in the room" and the effects of the language and skill sets of the performance disciplines as taught in the West.

We were working toward physio-vocal integration, searching for an integrative performance practice more in keeping with Basarab Nicolescu's notion of Transdisciplinarity which offers a way to think and practice beyond discipline. For Nicolescu, disciplinarity can be defined as one practice concerned with itself, with multi-disciplinarity as two disciplines operating in the same field but ultimately concerned with 
themselves. These are distinguished from inter- and plural disciplinarity, where both or all operate together, with an aim of transferability, but in the end return to their own spaces within the framework of their own disciplines. Transdisciplinarity "takes us beyond disciplines by weaving a new kind of knowledge" (Nicolescu 1997, pp.12-14). As the prefix "trans-" indicates, "transdisciplinarity concerns that which is at once between the disciplines, across the different disciplines, and beyond all discipline. Its goal is the understanding of the present world, one of the imperatives of which is the unity of knowledge"(lbid).

In considering current cross/inter-cultural discussions around performance practices, this study operates from the position that, "if multidisciplinarity and interdisciplinarity reinforce the dialogue between two cultures, transdisciplinarity permits us to envisage their open unification" (Nicolescu 2002, p.100).

Within Musical Theatre there is a term for a performer who dances, acts and sings: the triple threat. A good triple threat performer negotiates, coordinates and translates the disparate techniques as they fit into the required performance task. For the most part, this is multi- or interdisciplinary within Nicolescu's model. Artists that excel may find a personal embodied understanding that links the three into an integrated whole in 
moments of inspiration, but at present there is no one taught vocabulary or technique that offers a repeatable integrated practice.

\begin{abstract}
A fundamental issue is that the ways of breathing can differ quite drastically within voice and movement practices, with some dance methods completely omitting the instruction of how one even breathes and moves. Musical Theatre teachers like Pulliam sympathise, "Imagine being a student training in these three areas and you have mastered the breath technique taught in your singing studio, only to be told that you must breathe another way when speaking" (Pulliam 2009, p.59). This can indeed be complicated.
\end{abstract}

\begin{abstract}
As McGregor explains, with transdisciplinarity "there is a difference between a complicated situation and complex situation. A complicated problem is hard to solve because it is intricate and detailed. A complex problem has the additional feature of emergence, the process of deriving some new and coherent structures, patterns and properties." (McGregor 2007, p.2) With the work of EVDC, I was searching for an integrated practice towards an integrated outcome: the emergence of one vocabulary leading to one set of skills that would allow as its symptom an optimal use of the vocal body. Here, the performer would not negotiate or coordinate the languages and skill sets learned within the various
\end{abstract}


pedagogies of acting, dance/movement or singing/sounding, but rather they would do one thing as one artist, which would as a symptom allow for exacting voice and movement possibilities.

This aim presented some interesting dilemmas worth examination. As mentioned previously, each person in the room came from different disciplines, exposed to varied heritages of practices. Of course there are many great teachers of acting, voice and movement that come to the work with an intuitive understanding that to train best in any performance discipline a balanced, poised and integrated performance instrument must be cultivated. This work is indebted to such wonderful teachers, and, regrettably, in scope of this article all cannot be celebrated. Rather, I will critically reflect on the experience of the artists in this study with regard to the more general practitioner's dilemmas in coming from acting, singing or dance while working in a methodology of transdisciplinarity.

\section{The actor's dilemma}

The actors came from a tradition where voice and body work are mainly utilised in exercises for freeing up the instrument. From Stanislavsky through to today, movement, and then voice, are often positioned as preliminary steps for preparing the actor's instrument. As such, they are rendered separate moments on a linear path towards a greater aesthetic outcome 
grounded in text. Zinder clearly expresses reasons for this method of training:

Starting from the body, moving into voice work on a solid basis of the well-trained body, and only then moving into the fascinating, elusive, complex, and profound terrain of imagination. The basic premise here is that actor training needs to steer clear of voice, words, or text as long as possible, and to develop the training in that order: from the purely physical to the discovery of the sound produced by the moving body, and only then using well-trained, deeply connected body and voice to support the actor's work with words, language, and text. (Zinder 2002, p.5)

In this typical process, actors learn movement and voice exercises, honing the body and voice in preparation for the text, role or play, which ultimately gives the performance meaning.

In acting trainings that work in areas of voice/movement integration, we often get the sort of exercises which engage primal expressive qualities that allow for greater or freer expression for the purpose of taking the actor out of their heads and into their bodies. This is useful on its own terms towards creativity, but assumptions within this raise interesting issues. What we were presenting was not the free movement and sounding prevalent 
in the sixties, or the therapeutic personal catharsis that can come from guided non-verbal Dionysian movement and sound trance-like experiences. We were working in the realm of exacting disciplines for optimal voice and movement.

We found that even many acting trainings that aim to connect the disciplines start in an illusive space. For Lugering, working in voice and movement integration of the actor, "all sound and movement work is at its very core a type of abstraction" (Lugering 2009, p.14), with expressive action defined as "any physical action that simultaneously contains and reveals thought and feeling" (Lugering 2007, p.5). He further states that "when sound and movement exercises are structured based on the principles of expressive action, the student is acting in the abstract while simultaneously placing a special emphasis on the physical and vocal sensorial properties of the expressive action without recourse to the intellectual/verbal component." (Lugering 2009, p.15). Further, "the fact of the matter is that our body can yield to the experience of the expressive action without the intellectual assistance. When this occurs a much simpler and primal type of actor training occurs that is rooted in the movement, sound and sensation, rather than predetermined analysis and deliberation" (Ibid, p. 21). 
For us, however, in our requirement for complete integration of voice and movement, there was an imperative to integrate the "intellect", so as to execute exacting and precise physio-vocal challenges. We solved the problem of intellect/non-intellect by working from a place of awareness. As a result, we did not come from an idea that the intellect was an obstacle or that "the intellect is located in the space between our ears. It is what we commonly refer to as our mind" (Lugering 2007, p.10). Biophysicist Candace Pert summarises:

The Mind doesn't dominate body; it becomes body. Body and mind are one. I see the process of communication we have demonstrated, the flow of information throughout the whole organism, as evidence that the body is the actual outward manifestation, in physical space, of the mind.... Thus, it could be said that intelligence is located not only in the brain but in the cells that are distributed throughout the body, and that the traditional separation of mental processes, including emotions, from the body is no longer valid. (Pert 1997, p.187).

\begin{abstract}
Working on this basis allowed us to circumvent much of the contemporary fetishising around the Cartesian mind/body split, along with any claim that our work was a reconfigured version of "psycho-physical" practice. With
\end{abstract}


Transdisciplinarity as our methodology and integration as our goal, the mere recognition of these dualities would have thrown us into binary relationships directly at odds with the very premise of integration and trandisciplinarity. For us, the mind became the vocal-body, with expression, text and intention, vocal, physical or emotive, all fueled and sustained by breath from awareness.

\section{The vocalist's dilemma}

When first beginning, I mistakenly assumed that those that had studied voice, understanding the importance of breath, would have the most coherent skills sets and vocabulary for an emerging vocal-dancer. Ironically, we found that it was the singers that had the most difficulty in working towards sounding and moving. This often came as a result of having worked extra hard to protect, learn and establish a personal practice of breath support.

So often a vocalist is taught to breathe almost as if they had never breathed before, or had once done so in a purer state. They are told that as a child they had breathed more freely and more in tune with their bodies. They learn that there have been things put in the way of this optimum breath, which could include personal histories, illness and possible trauma, that have created learned physical patternings that may 
have resulted in blocks that adversely effect the voice. This can be helpful to an extent; however, when taught this way, it presents a relationship to breath and voice that creates a peculiar and precious protection mechanism when one finds they have mastered their damage. We worked hard not to judge or diagnose or focus on these aspects (which may include tension, a bad day, emotional uprisings...); we rather allowed and witnessed to create a less ego-centred relationship than that which invariably situates the me as subject and breath-support as object. We are our breath, after all. We worked with the vocal-body and with voice as a breath-dance. This is supported by the master of breath, Thich Nhat Hanh:

Breathing and body are one. Mind and body are one. At the time of observation, mind is not an entity which exists independently, outside of your breathing and your body. The boundary between the subject of observation and the object of observation no longer exists. We observe 'the body in the body'. (Hanh 1988, p.48)

In some respected vocal trainings breath is often learned in positions to bring awareness to proper breathing alignment and/or posture. The differences between standing and singing an aria that one has performed successfully many times in front of a piano and singing while rolling, leaping, walking or moving from standing to the floor can 
completely demolish this learned architecture of support. As a result, we found a need to completely re-examine what the value of our learned support was. We found that even with the artists familiar with somatic practices such as Alexander Technique, Body Mind-Centering and Feldenkrais, for the extreme movements that took us out of everyday standing, sitting and walking, these practices were limited. We found that none of the somatic practices, on their own, offered a vocabulary or a skill set that allowed for coordination with the kind of sustained breath required for singing while moving in more extreme ways.

\title{
The dancer's dilemma
}

We worked with a specific breathing practice that starts from a slightly different sense of centre than any of the acting, singing or dance practices that we had encountered. We worked with dynamic alignment through an understanding of our kinetic anatomy, not within the realm of posture or positions.

\author{
As touched on previously, many traditional dance practices do not \\ address breath in motion. Understandably, they revolve more around \\ issues of line, extension, flexibility and strength. The high point of centre in \\ the body of Ballet, for instance, often creates a high and shallow \\ breathing; further, Jazz and Tap, when taught as a progression from the
}


physical vocabulary of Ballet, requires a held maintenance of the trunk of the body for aesthetic purposes. In this type of training, maintaining a position in the upper body renders impossible the kind of full-body breath that needs flexibility in the intercostals (lower ribs) and, most importantly, the release of the pelvic floor on the intake of breath. This is not to say that it is impossible to dance in the forms of Ballet, Jazz or Tap while singing to one's optimal capability. It simply means that a different approach to the aesthetics of movement is required, different from form and genre (i.e aesthetic): a way of doing (active aesthetic), entering from awareness through dynamics of the breath-body so that required line, flexibility, and even strength become symptoms of an integrated practice.

\author{
Strength, as earned by way of attaining certain positions or mastering \\ movement sequences hung on static form, can create the type of \\ tensions that impede the breath-body. In exploring movement and sound \\ as a breath-dance we found that often the dancers in the room had to \\ release habitual muscular holding, even while doing the same sort of \\ movement sequences they were used to in dance. We found that the \\ breath itself could provide the sort of dynamic strength that the muscle \\ was known to hold. This is not unlike the work of modern \\ dancer/choreographer Erick Hawkins, mentioned previously:
}


The key concept-and the secret behind a Hawkins dancer's unbound, soft muscled quality-is contraction and de-contraction. This does not imply movement that is not performed fully; rather it suggests using only the effort required to perform efficiently. (Stern 2007)

Hawkins also believed in the integration of the intellect. "Hawkins invented a word to use in the classroom when he is trying to reveal to a student how to develop kinesthetic awareness, "think-feel"'" (Brown 1971, p.12). The term is not about being in the body with a position of no-mind or pure experience. In vocal-dance this would be considered disintegrating. Hawkins' term has similarities with way that we use awareness rather than focus and witnessing rather than judging and diagnosing. For us however this goes beyond a concept and further is a practical foundation of the work as mentioned earlier.

In general, Modern Dance tends to inhabit a lower point of centre in the body than Ballet. This is often made apparent through the learning of contractions. The contraction part of the contraction/release that a dancer grounded in Martha Graham's technique learns is often taught as a movement stemming from the feeling of being punched in the lower belly, or from a percussive exhale that happens in a laugh or a scream, 
resulting in a 'natural' curvature of the spine with a hollowing of the lower belly. This 'pelvic' centre presents difficulties for a vocal dancer wishing to sound on the exhale and while doing the shape of a 'release'. In Hawkins' work, movement starts by "initiating and controlling movement from the body's pelvic centre of gravity; swinging the legs from high in the hip socket to activate lightness and freedom finding the body's midline through the spine's four curves—cervical, thoracic, lumbar and sacral" (Stern 2007). In Pilates, which many modern dancers use to condition, there is a "scooping" of the lower belly or drawing of the "navel towards the spine" (Siler 2000, p.20). Although with good training this is not considered the same as "sucking in your tummy", even done correctly we found that this created difficulties in the complete release needed of the pelvic floor on the intake. What we found was that we needed to clarify the action of an even lower point of centre than generally used in acting, voice or movement practices, the perineum - a centre connected with a vertical movement of breath rather than horizontal, one that would integrate the practitioner in the act of practice and allow for full physiovocal capabilities.

\section{Conclusion}

While working not by putting voice and movement together but rather from a transdiciplinary perspective, new vocabulary and skill sets 
emerged. We created not from the aesthetics of voice or movement, but rather through an active aesthetic that allowed for exacting voice and movement possibilities. The use of awareness was increasingly essential as the need for choreographic and vocal challenges grew. "Return to centre" became our motto. Practitioners found that the work we did not only translated well to their work as actors, singers and dancers but enhanced their technique(s). There are many paths, but I hope this provides a different and interesting entry into the discussion of physiovocal integration. We invite you to play with our discoveries and take them further within your own practice(s).

Bibliography;

Barba, E. and Savarese, N., 2006. A Dictionary of Theatre Anthropology, The Secret Art of the Performer. 2nd Ed. London: Routledge. Basarab, N., 2002 Manifesto of Transdiscplinarity, Translated from French by Karen-Claire. NY: SUNY Press.

Basarab, N., The Transdisciplinary Evolution of the University Condition for Sustainable Development. (The International Association of Universities) International Congress, Universities', International Congress, Universities' Responsibilities to Society. Bangkok, Thailand, November 12-14, 1997. Chulalongkorn University Benedetti, R., 1997. The Actor at Work. $7^{\text {th }}$ Ed. Allyn and Bacon. USA. 
Brown, B., 1971. Training to Dance with Erick Hawkins. Dance Scope, 6 winter/fall issue, pp.6-30.

Bryon, E, 2006. exdcny Workshop Report posted to evdc@yahoogroups.com December 8, 2006, 15:28:29 GMT. Available at: http://groups.yahoo.com/group/evdcny/ (Accessed 8 May 2011) Buddhananda, Swami, 1996. Moola Bandha, The Master Key. New Delhi India: Yoga publications Trust, Thomson Press.

Franklin, E., 2002. Pelvic Power, Mind/body Exercises for Strength, Flexibility, posture, and Balance. NJ: Princeton Book Company.

Hanh, T.N., 1988. The Sutra on the Full Awareness of Breathing. Ed. Berkeley, CA: Parallax Press.

Jolicoeur, K., 2007. RE: evdcny Rehearsal Report 11/9 [Yahoo group discussion] posted to evdc@yahoogroups.com November 10, 2007. 16:01:42 GMT. Available at: http://groups.yahoo.com/group/evdcny/ (Accessed 8 May 2011) Koch, L., 1997. The Psoas Book. CA: Guinea Pig Publications. Lugering, M., 2007. The Expressive Actor, Integrated Voice Movement, and Acting Training. NH:Heinman.

McGregor, S., 2007. The Nature of Transdisciplinary Research and Practice. International Journal of Consumer Studies, 31 (1), P.2.

Paton, J.G. ed.1975., Nicola Vaccai Practical Method of Italian Singing. NYC: Shirmer, Inc. 


\author{
Pert, C. B., 1997. Molecules of Emotion The Science Behind Mind-Body \\ Medicine. New York: Scriber \\ Pullian, R., 2006. Training the Musical Theatre Performer: Finding a Unified \\ Breath in : R. Cook ed. 2006. The Moving Voice. USA: VASTA, pp.59-66. \\ Siler, B. 2000. The Pilates Body. NY: Broadway Books. \\ Stern, C., 2007. Erick Hawkins Modern Dance Maverick, Dance Teacher \\ Magazine, Macfadden Performing Arts Media [online] Available at \\ http://www.highbeam.com/doc/1P3-1339996471.html , [Accessed 15
}

May 2011].

Zarrilli, P. 2009. Psychophysical Acting, An Intercultural Approach after

Stanislavsky. London: Routledge.

Zarrilli, P. 2000. Kathakali Dance-Drama: Where Gods and Demons come to Play. London: Routledge. 


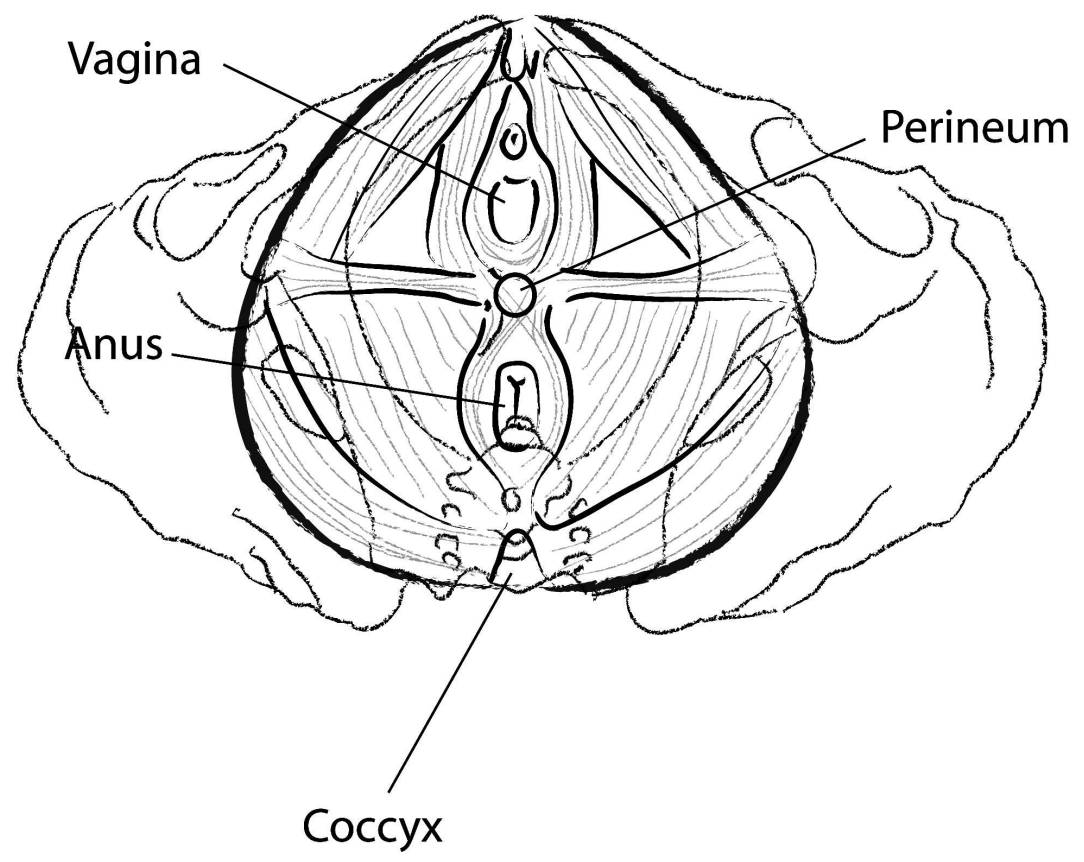

P. Zacharek @2008

$203 \times 152 \mathrm{~mm}(300 \times 300$ DPI $)$ 


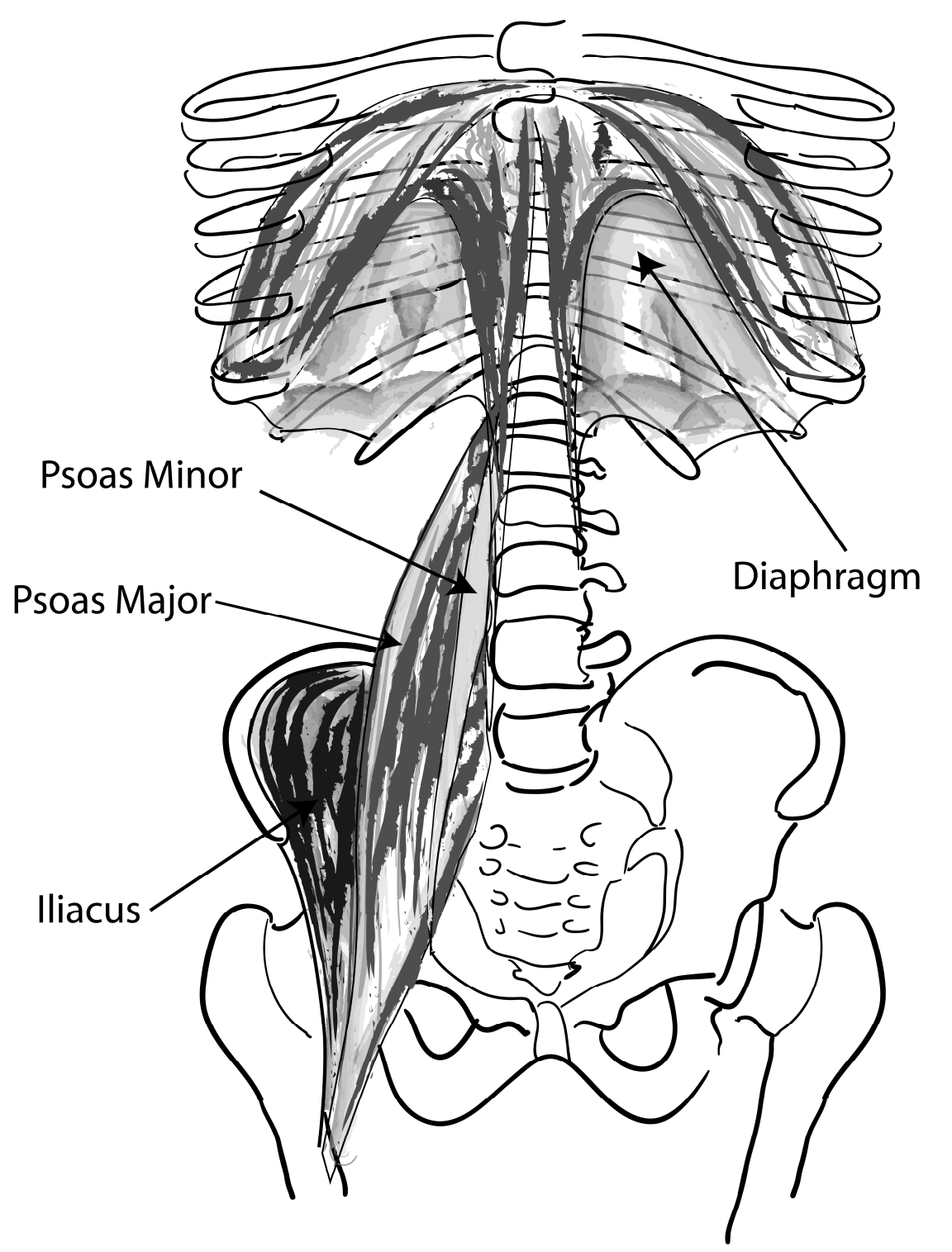

P. Zacharek $\odot 2007$

$445 \times 579 \mathrm{~mm}(300 \times 300 \mathrm{DPI})$ 


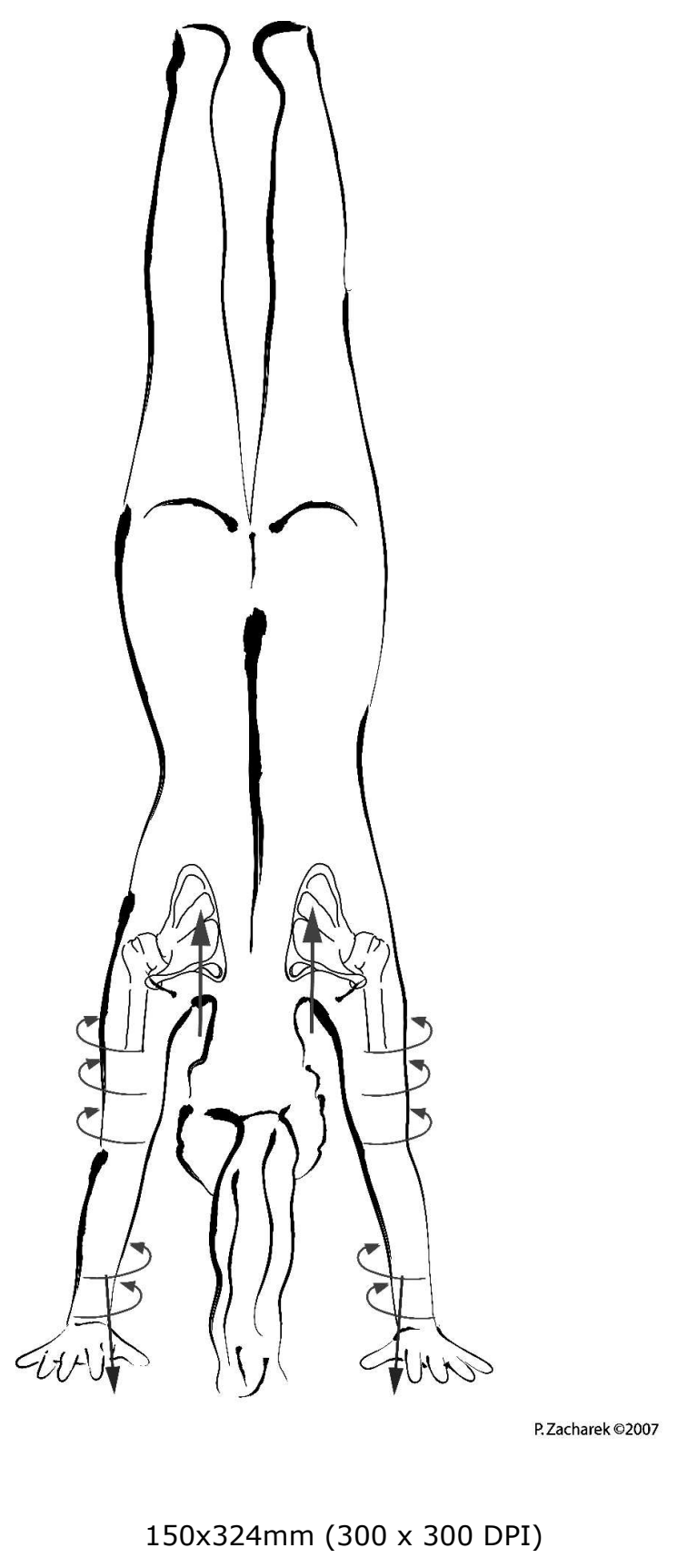

1

2

3

4

5

6
7

8

9

10

11

12

13

14

15

16

17

18

19

20

21

22

23

24

25

26

27

28

29

30

31

32

33

34

35

36

37

38

39

40

41

42

43

44

45

46

47

48

49

50

51

52

53

54

55

56

57

58

59

60

URL: http://mc.manuscriptcentral.com/rtdp 
Theatre, Dance and Performance Training

Page 40 of 45

\begin{tabular}{l}
1 \\
2 \\
3 \\
4 \\
5 \\
6 \\
7 \\
8 \\
9 \\
10 \\
11 \\
12 \\
13 \\
14 \\
15 \\
16 \\
17 \\
18 \\
19 \\
20 \\
21 \\
22 \\
23 \\
24 \\
25 \\
26 \\
27 \\
28 \\
29 \\
30 \\
31 \\
32 \\
33 \\
34 \\
35 \\
36 \\
37 \\
38 \\
39 \\
40 \\
41 \\
42 \\
43 \\
44 \\
45 \\
46 \\
47 \\
48 \\
59 \\
50 \\
51 \\
52 \\
5 \\
\hline
\end{tabular}

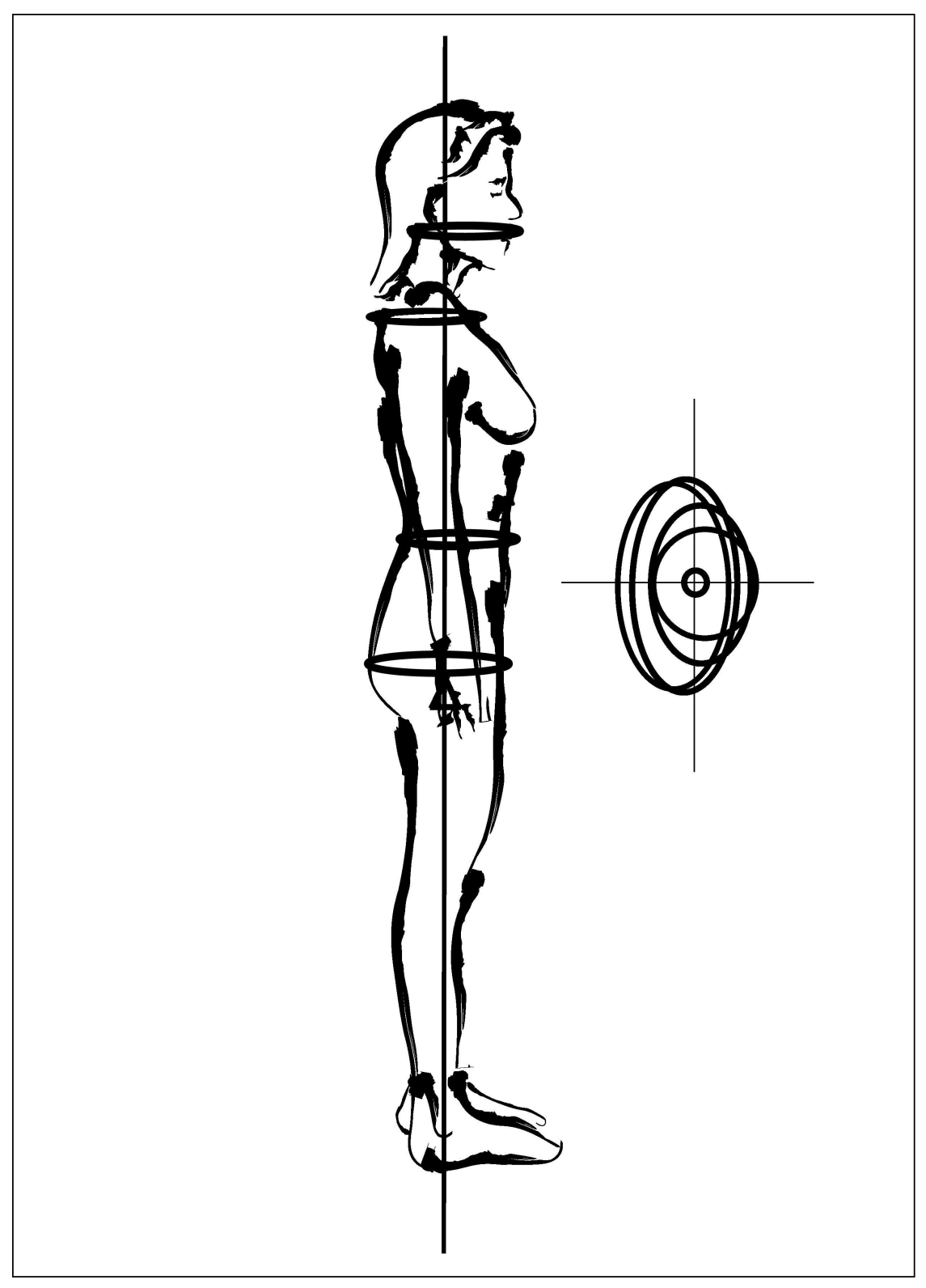

$214 \times 299 \mathrm{~mm}(300 \times 300 \mathrm{DPI})$

URL: http://mc.manuscriptcentral.com/rtdp 

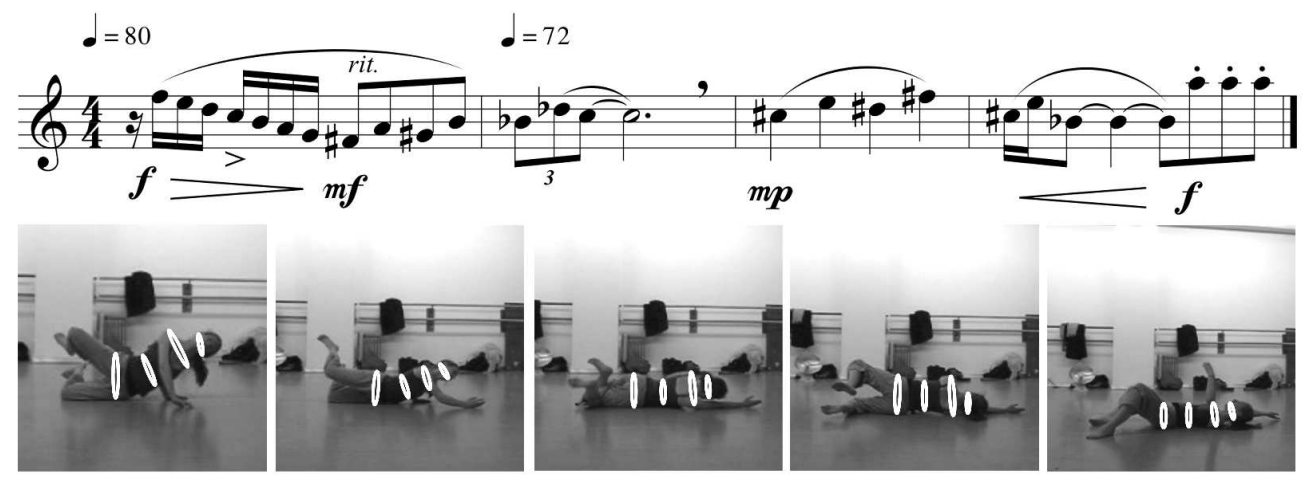

$414 \times 156 \mathrm{~mm}(300 \times 300 \mathrm{DPI})$ 


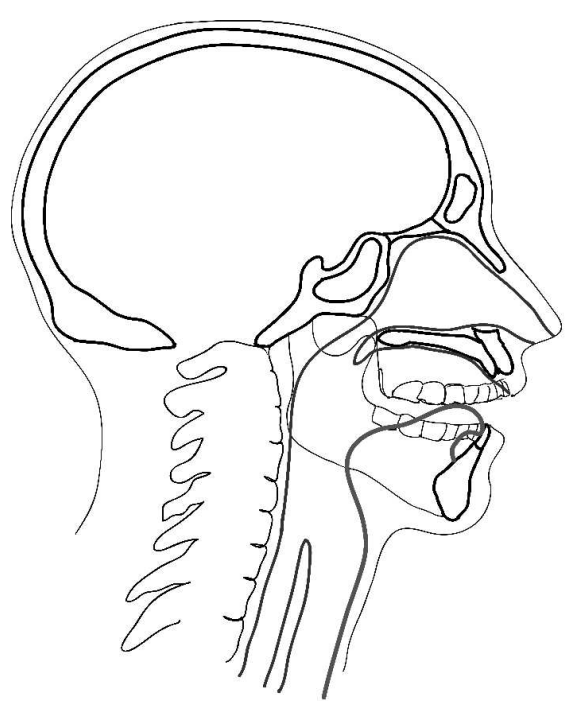

Intake

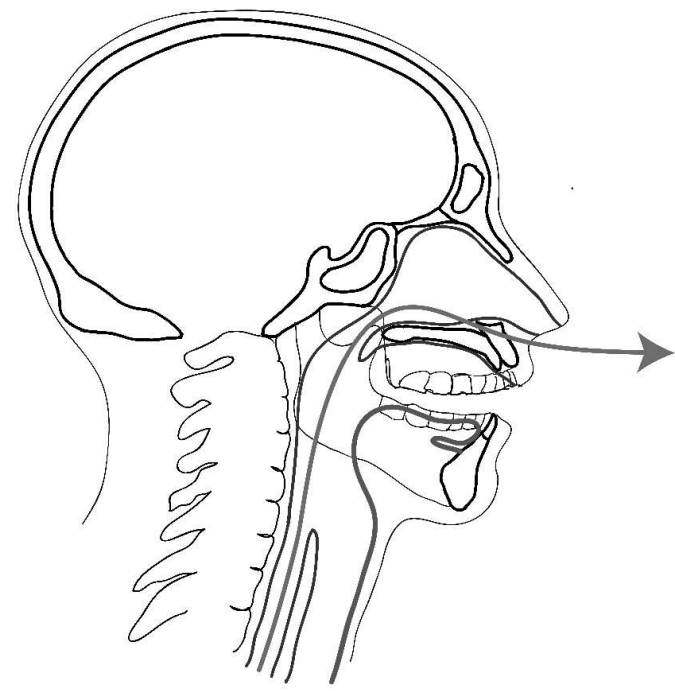

Voicing 


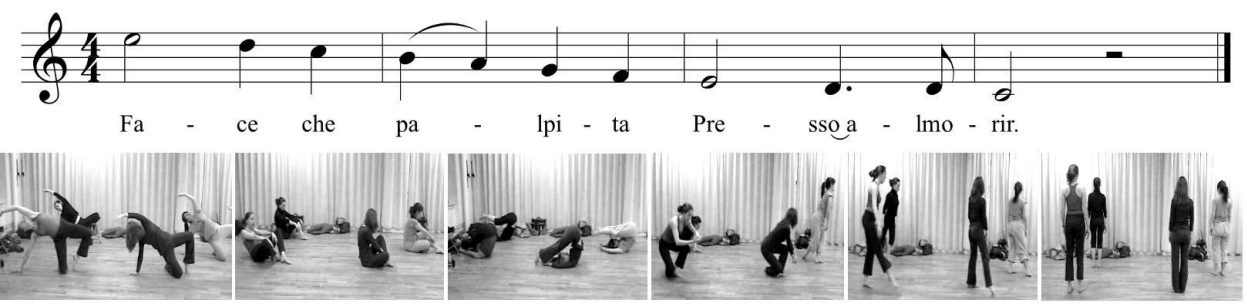

$430 \times 105 \mathrm{~mm}(300 \times 300 \mathrm{DPI})$ 
Theatre, Dance and Performance Training

Page 44 of 45

1
2
3
4
5
6
7
8
9
10
11
12
13
14
15
16
17
18
19
20
21
22
23
24
25
26
27
28
29
30
31
32
33
34
35
36
37
38
39
40
41
42
43
44
45
46
47
48
49
50
51
52
53
54
55
56
58
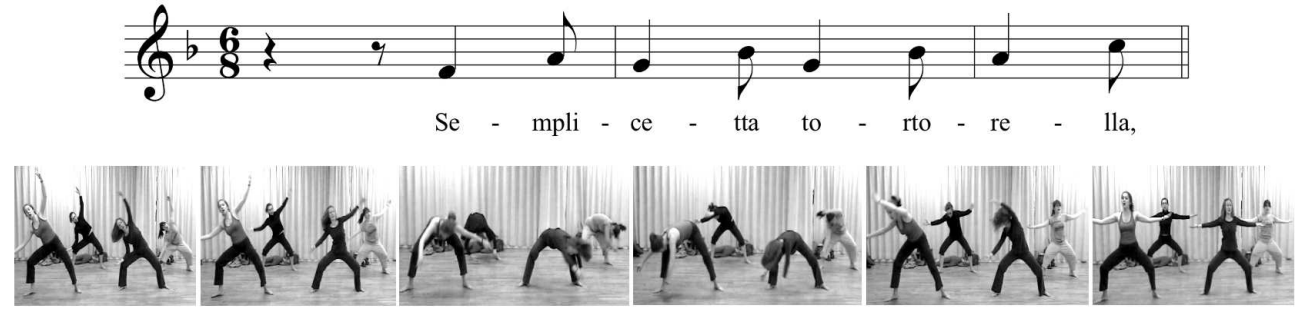

$430 \times 108 \mathrm{~mm}(300 \times 300 \mathrm{DPI})$

URL: http://mc.manuscriptcentral.com/rtdp 


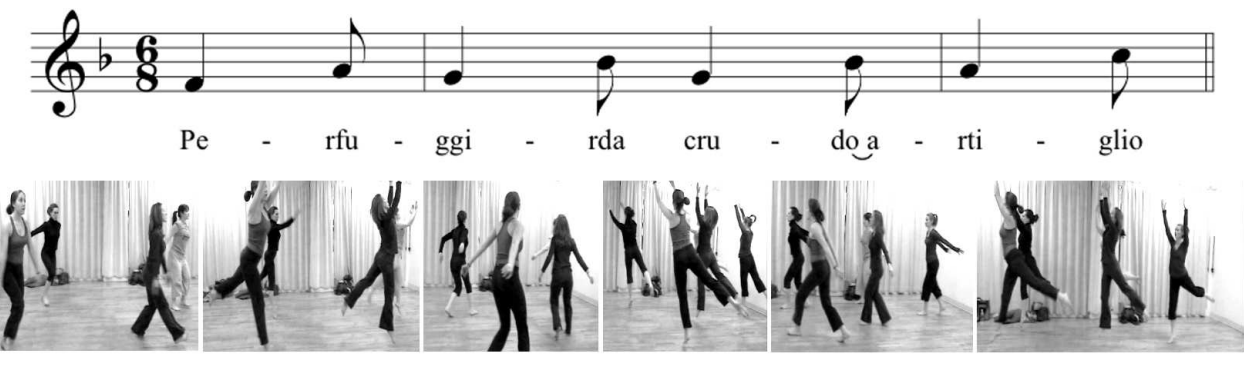

$430 \times 120 \mathrm{~mm}(300 \times 300$ DPI $)$ 